\title{
Preface from Editor in Chief
}

Bin Yang ${ }^{1}$

(c) The Nonferrous Metals Society of China 2019
Welcome to the inaugural issue of Tungsten, a new peerreviewed academic journal of its kind. The publication of the journal has a far-reaching significance to both the nonferrous metals industry of the world and Jiangxi University of Science and Technology (JXUST), one of the organizers of the journal.

China, the world's largest tungsten ore resources owner and producer, plays an important role in tungsten industry all over the world. JXUST, located in Ganzhou which is widely known as "the tungsten capital of the world" due to its abundant tungsten resources, has made a series of academic and technological breakthroughs in the basic theory and application technology of tungsten. Based on impressive achievement, growing interest in the field and district advantages, the Nonferrous Metals Society of China (Nfsoc) and JXUST take the initiative in founding the journal to support the original innovation in the tungsten field and serve the high-quality development of tungsten and related industries.

The journal focuses on all aspects of tungsten and related metals, including molybdenum, cobalt, vanadium, tantalum, niobium, rhenium, as well as their alloys and compounds. The editorial board of the journal consists of well-known experts at home and abroad and we have the great pleasure to invite Dr. Jinshu Wang from Beijing University of Technology, Dr. Guangnan Luo from Institute of Plasma Physics Chinese Academy of Sciences, Dr. Guanghong Lu from Beihang University, Dr. Lianzhou Wang from the University of Queensland, Australia and Dr. Gregory De Temmerman from the International Thermonuclear Experimental Reactor (ITER) organization, France as Associate Editors. In cooperation with Springer Nature Group, a world-class publisher, we will provide researchers with efficient service featured with full range, high quality and high level. The journal is

Bin Yang

yangbin@jxust.edu.cn

1 Jiangxi University of Science and Technology,

Ganzhou 341000, China home to scientific experts and technological engineers in tungsten and related fields all over the world.

I sincerely hope that experts at home and abroad will give warm support to the journal and strive to make it a worldclass platform for the academic exchange. Finally, I would like to thank all the editorial board members, experts, editors and authors who make great efforts for the successful publication of the journal. I wish Tungsten a bright future!

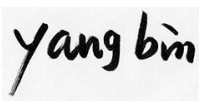

Bin Yang

March 20, 2019

Publisher's Note Springer Nature remains neutral with regard to jurisdictional claims in published maps and institutional affiliations.

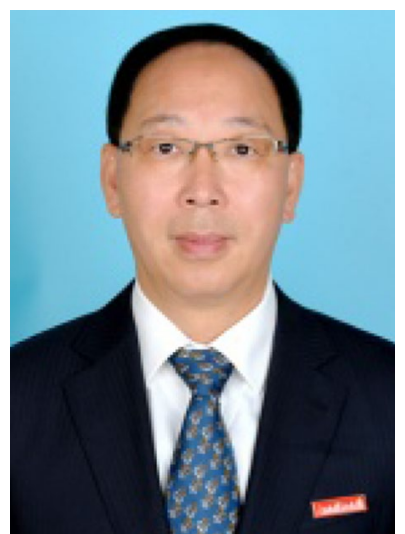

Dr. Bin Yang received a Ph.D degree in Material Science and Engineering from University of Science and Technology Beijing. $\mathrm{He}$ is the president of Jiangxi University of Science and Technology, China. He also serves as the deputy chair of the Nonferrous Metals Society of China (Nfsoc), a member of the China Nonferrous Metals Industry Association Expert Committee, and the deputy director of the National Research Center for Copper Smelting and Processing Technology. His research area primarily focuses on the 
development of new nonferrous metal materials, new technologies and new equipments. He has authored and co-authored over 90 original research papers in the field of material science and engineering. He is the chief scientist of the National High-tech R\&D Program (863 Program), principal investigator of 6 nationally funded research grants, and inventor of 20 patents. He is also the principal investigator of over 60 research projects funded by some major non-ferrous metal enterprises of China. He is the recipient or co-recipient of 3 provincial science and technology achievement awards. 